\title{
Role of Central Epinephrine in Regulation of Anterior Pituitary Hormone Secretion ${ }^{1}$
}

\author{
L. CASS TERRY, ${ }^{2}$ W. R. CROWLEY, ${ }^{3}$ C. LYNCH, C. LONGSERRE \\ AND M. D. JOHNSON \\ VA Medical Center and Department of Neurology, University of Michigan, Ann Arbor, MI 48105 \\ and Department of Pharmacology, University of Tennessee Center for Health Sciences, Memphis, TN 38163
}

\begin{abstract}
TERRY, L. C., W. R. CROWLEY, C. LYNCH, C. LONGSERRE AND M. D. JOHNSON. Role of central epinephrine in regulation of anterior pituitary hormone secretion. PEPTIDES 3(3) 311-318, 1982.- Hypothalamic regulation of anterior pituitary hormones is thought to be mediated by the release of stimulatory and/or inhibitory peptides that are, in turn, regulated by catecholaminergic neurons. The recent development of selective epinephrine (EPI) synthesis inhibitors has made it possible to disrupt central EPI neurotransmission without affecting norepinephrine or dopamine. These compounds were used in the present investigation to assess the involvement of brain EPI systems in regulation of GH, LH, and prolactin (PRL) in male and ovariectomized female rats. Inhibition of central EPI synthesis (1) inhibited episodic and morphine-, but not clonidine-induced GH release, and (2) blocked the LH surge induced by estrogen and progesterone, but did not affect episodic LH release in hormonally untreated rats. Inhibition of peripheral (adrenal) EPI synthesis had no effect on these hormones. Results of these studies suggest an excitatory role for EPI in regulation of GH and LH secretion, mediated by stimulation of GH-releasing hormone and LHRH, respectively. EPI does not appear to have a major function in regulation of PRL secretion.
\end{abstract}

Epinephrine Growth hormone Luteinizing hormone Prolactin Neurotransmitters Hypothalamus

THE hypothalamus contains a number of neurotransmitters and the enzymes involved in their synthesis. There is growing evidence that these substances modulate hypothalamic peptidergic nerve function or are themselves released into the portal system to act on pituitary receptors and thereby influence hormone release.

Substantial quantities of dopamine (DA) and norepinephrine (NE) are found in the median eminence and in various hypothalamic nuclei of the rat $[14,33,34,38]$. Epinephrine (EPI) and the EPI-forming enzyme, norepinephrine-Nmethyltransferase (NMT) are also found in the hypothalamus $[12,14,20,34]$. These neurotransmitters are concentrated in the same regions of the hypothalamus and median eminence that are rich in regulatory peptides [14], suggesting a functional relationship.

Growth hormone (GH) secretion by the pituitary gland appears to be regulated by two hypothalamic hormones, one stimulatory (GH-releasing factor) and the other inhibitory (somatostatin, SRIF). Although there is substantial physiological and biochemical evidence for the existence of GHreleasing factor, its structure has not been determined [29]. Somatostatin has been characterized as a tetradecapeptide [2]. Extensive studies in man and experimental animals suggest that the release of SRIF and GH-releasing factor is regulated by catecholamine-containing neurons in the central nervous system (CNS) $[28,29]$.

CNS alpha-adrenergic receptor stimulation with clonidine elicits $\mathbf{G H}$ release in man [26] and a number of lower species $[3,9,26,50,51]$. Evidence concerning the role of brain DA receptors in GH control is less consistent. In man, CNS DA receptor stimulation causes GH release [23]. However, activation or blockade of DA receptors in experimental animals has little effect on $\mathrm{GH}[3,9,26]$, indicating that its effects may be specific to man.

Previous investigations have demonstrated that NE synthesis inhibitors and receptor antagonists prevent preovulatory and estradiol plus progesterone-induced surges of luteinizing hormone (LH) and prolactin (PRL) [6, 16-18]. This has led to the hypothesis that the stimulatory feedback actions of the ovarian hormones, estradiol and progesterone, on LH and PRL secretion involve activation of central noradrenergic systems, which in turn regulate luteinizing hormone-releasing hormone (LHRH) release [43].

Extensive evidence indicates that DA is important in the control of prolactin PRL secretion in animals and man, and that DA is most likely PRL inhibiting factor $[21,22,27]$. The role of the central NE system in regulation of PRL secretion is not clear and the available information is contradictory.

\footnotetext{
${ }^{1}$ This work was supported by NIH Grants AM-31098 (to LCT) and HD-13703 (to WRC) and by the Medical Research Service of the Veterans Administration (to LCT).

${ }^{2}$ Recipient of a VA Clinical Investigator Award. Please send reprint requests to Dr. L. Cass Terry, VA Medical Center, Neurology (127), 2215 Fuller Rd., Ann Arbor, MI 48105.

${ }^{3}$ Recipient of a Research Career Development Award (HD-00366).
} 
Systemic administration of clonidine to experimental animals causes elevation of PRL levels $[9,25,48,51]$. Administration of phenoxybenzamine has a similar effect, whereas alpha-blockade with phentolamine or beta-blockade with propranolol has no consistent influence $[25,30]$.

In the studies described above, noradrenergic agonists and antagonists used may also have affected transmission in EPI (adrenergic) systems. Results of earlier experiments suggest that EPI stimulates GH release in primates [32] and rodents $[36,37]$ but not in man $[36,42]$. This catecholamine is also a potent stimulant of LH release in rats [43], whereas its role in regulation of PRL secretion is unknown.

The availability of several selective EPI synthesis inhibitors, developed for possible use as antihypertensive agents in man $[10,39,40,45]$, have made it possible to alter the synthesis of EPI without affecting NE or DA. These compounds have been used in the present investigation to assess the involvement of brain EPI systems in regulation of GH, LH and PRL secretion in the rat. Results of these studies indicate that the CNS adrenergic system has a major function in the regulation of $\mathrm{GH}$ and $\mathrm{LH}$ secretion by hypothalamic peptides.

\section{METHOD}

\section{Animals}

Male and ovariectomized female Sprague-Dawley rats $(300-500 \mathrm{~g})$ were housed in temperature- and humiditycontrolled laboratories with a 12-12 or 14-10 hr light-dark cycle (lights on at 0600 ). The animals were given free access to laboratory chow and water.

\section{Norepinephrine-N-Methyltransferase (NMT, EC2.1.1.28) Inhibitors}

The selective EPI synthesis inhibitors, SK\&F 64139, 83593 and 29661 (7,8-dichloro-1,2,3,4-tetrahydroisoquinoline, chloro-tetrahydroisoquinoline-7-sulfonamide, and 1,2,3,4-tetrahydroisoquinoline-7-sulfonamide, respectively; Smith, Kline \& French Laboratories, Philadelphia, PA), which act by inhibiting NMT, were dissolved in $0.15 \mathrm{M} \mathrm{NaCl}$ (pH 7.0) to yield a final concentration of $25 \mathrm{mg} / \mathrm{ml}$ and administered intraperitoneally in doses of 10,25 , and $50 \mathrm{mg} / \mathrm{kg}$ body weight. A fourth NMT inhibitor, LY 78335 (2,3dichloro- $\alpha$-methylbenzylamine; Eli Lilly and Company Research Laboratories, Indianapolis, IN) was dissolved in the same vehicle and administered intraperitoneally in doses of 25 and $50 \mathrm{mg} / \mathrm{kg}$ body wt. SK\&F 64139, 83593 and LY 78335 cross the blood-brain barrier and inhibit central and peripheral EPI synthesis $[10,45]$. SK\&F 29661 inhibits only peripheral EPI synthesis, because it does not cross the blood-brain barrier [40].

\section{Experimental Procedure}

Experiment 1 . Chronic indwelling cannulae were placed in the right atrium via the right external jugular vein and adapted to isolation test chambers by methods described previously [50]. Blood samples were withdrawn every $15 \mathrm{~min}$ and centrifuged immediately. The plasma was frozen at $-90^{\circ} \mathrm{C}$ until radioimmunoassay of $\mathrm{GH}, \mathrm{LH}$ and PRL, and erythrocytes suspended in physiological saline were returned to the animals at the time of the next sample. Individual rats were used as their own control, receiving control injections one experimental day and the drug(s) to be tested on a subsequent day. Animals received either the centrally active EPI synthesis inhibitors, SK\&F 64139 and LY 78335 , the peripherally active, SK\&F 29661 , or saline vehicle at $0930 \mathrm{hr}$ and were sampled for $3 \mathrm{hr}$ or $6 \mathrm{hr}$ beginning at 1000 hr. The animals' behaviour was monitored through one-way observation ports in the cubicles.

In a parallel experiment, male rats were killed by cervical dislocation 1.5, 2.5, and $3.5 \mathrm{hr}$ after receiving either SK\&F 64139,29661 , or normal saline at $0930 \mathrm{hr}$. Their brains were removed immediately, and hypothalami were dissected, weighed, snap-frozen on dry ice, and stored at $-90^{\circ} \mathrm{C}$ for subsequent extraction and determination of DA, NE, and EPI, as described previously [50].

Experiment 2. To investigate the effects of alphaadrenergic receptor activation on $\mathrm{GH}$ after EPI depletion, clonidine $(150 \mu \mathrm{g} / \mathrm{kg} \mathrm{IV})$ or vehicle was given to $\mathrm{SK} \& \mathrm{~F}$ 64139-pretreated animals at $1105 \mathrm{hr}$ by methods described for Experiment 1

Experiment 3. To determine whether blockade of central EPI synthesis affected morphine-stimulated GH, morphine sulfate ( $3 \mathrm{mg} / \mathrm{kg} \mathrm{IV)}$ or normal saline was administered at $1105 \mathrm{hr}$ to animals pretreated with either SK\&F 64139 or vehicle at $0930 \mathrm{hr}$. Samples were removed from 1000-1300 $\mathrm{hr}$, as described above.

Experiment 4. Female rats were ovariectomized and allowed four weeks for recovery, during which time they were maintained on a $14 \mathrm{hr}$ light/10 hr dark schedule and ad lib food and water. In a first experiment, the females received injections (SC) of either oil vehicle or $50 \mu \mathrm{g}$ estradiol benzoate, followed $72 \mathrm{hr}$ later by either oil vehicle again or by 2 mg progesterone. Animals were sacrificed by cervical dislocation $6 \mathrm{hr}$ after progesterone. Thirty minutes before and 2.5 $\mathrm{hr}$ after progesterone or oil, animals received injections (IP) of either saline vehicle, or the centrally acting EPI synthesis inhibitors, SK\&F 64139 (50 mg/kg) or SK\&F 83593 (50 or 100 $\mathrm{mg} / \mathrm{kg})$, or the peripherally active, SK\&F $29661(50 \mathrm{mg} / \mathrm{kg})$. Plasma LH and PRL concentrations and hypothalamic catecholamines were measured in each group.

Experiment 5. Ovariectomized females received estradiol followed by progesterone, as described above. Thirty minutes prior to the progesterone, animals were given IP injections of either saline or of $50 \mathrm{mg} / \mathrm{kg}$ of SK\&F 64139 . Two hours after progesterone, all animals received injections (IV) of either saline or of $100 \mathrm{ng}$ of LHRH. Blood samples were taken $15 \mathrm{~min}$ after LHRH or saline and assayed for LH.

Experiment 6. Ovariectomized females received injections (SC) of either oil or estradiol at $1000 \mathrm{hr}$ and were killed at $1600 \mathrm{hr}$ on the next day, and plasma PRL concentrations were determined. Thirty minutes prior to estradiol, the females were treated (IP) with either saline or the EPI synthesis inhibitor, SK\&F $64139(50 \mathrm{mg} / \mathrm{kg})$. These drug treatments were repeated at 2000,0400 and $1200 \mathrm{hr}$.

\section{Pituitary Hormone Radioimmunoassays}

GH, LH and PRL were measured in duplicate by double antibody radioimmunoassays with materials supplied by the National Pituitary Agency, as described previously [7,52]. Values were determined using the weighted Rodbard method [52] and expressed in terms of their respective NIAMDD reference preparations.

\section{Catecholamine Assay}

Concentrations of EPI, NE, and DA in the hypothalamus were measured by a sensitive radioenzymatic assay, as described previously $[7,50]$. 


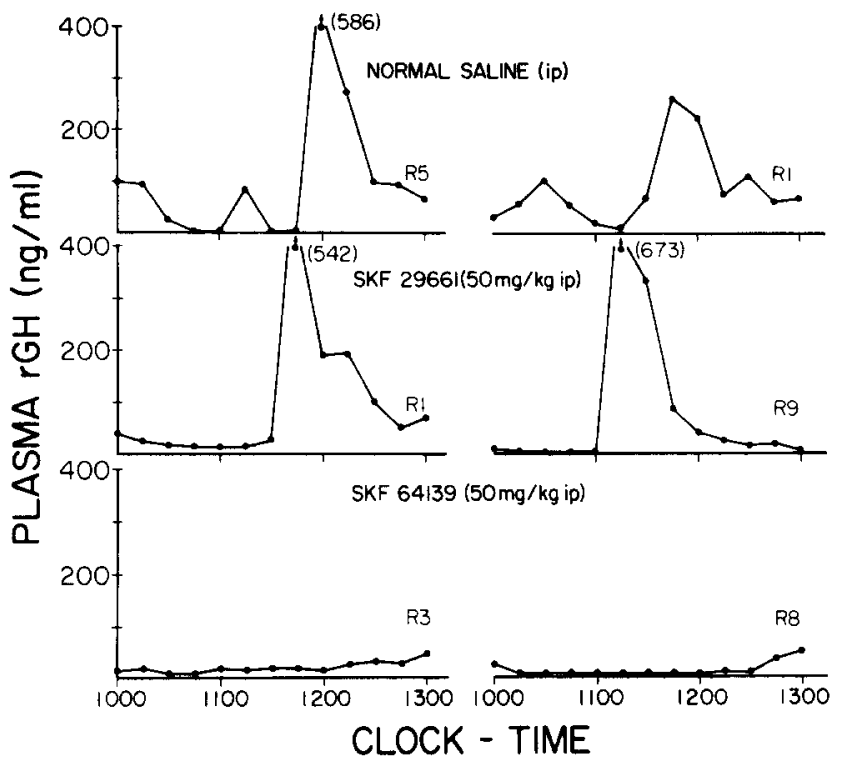

FIG. 1. Effects of SK\&F 29661, a peripheral EPI synthesis inhibitor, and SK\&F 64139 on episodic GH secretion in individual male rats. Normal saline- and SK\&F 29661-treated animals showed plulsatile GH release (top and middle, respectively). SK\&F 64139 completely suppressed episodic GH secretion (bottom). The letter R followed by a number in the lower right corner of each graph refers to individual rat code numbers in this and subsequent figures.

\section{Analysis of Data}

Pituitary hormone and tissue catecholamine levels were compared using the appropriate analysis of variance and Newman-Keuls tests, as described previously [7,50]. $p<0.05$ was considered significant.

\section{RESULTS}

Effects of NMT Inhibitors on Episodic GH Secretion in Male and Ovariectomized Female Rats

The pattern of GH secretion in individual animals confirmed previous observations $[49,52]$ that male rats kept on a constant light-dark cycle secrete $\mathrm{GH}$ at approximately the same time (Fig. 1, top). The centrally active SK\&F 64139 suppressed $(p<0.001)$ pulsatile GH (Fig. 1, bottom) in a dose-dependent manner. Administration of the other centrally active EPI antagonist, LY 78335, also suppressed $(p<0.001) \mathrm{GH}$ release in a similar manner (not shown, 50). However, the peripheral NMT inhibitor, SK\&F 29661, had no effect on GH when compared with the control group (Fig. 1 , middle). Similar effects on GH were observed in ovariectomized female rats (Fig. 2).

As demonstrated previously $[8,45,50]$, SK\&F 64139 caused a significant reduction $(p<0.05)$ in the hypothalamic concentration of EPI in male rats from 1.5 to $3.5 \mathrm{hr}$ after administration, whereas SK\&F 29661 had no effect when compared to time-matched controls (Fig. 3). Neither of the drugs affected tissue levels of DA or NE (not shown, 50).

To test whether the inhibition of GH release by SK\&F 64139 could be reversed by activation of central postsynaptic alpha-adrenergic receptors, clonidine or vehicle were ad-

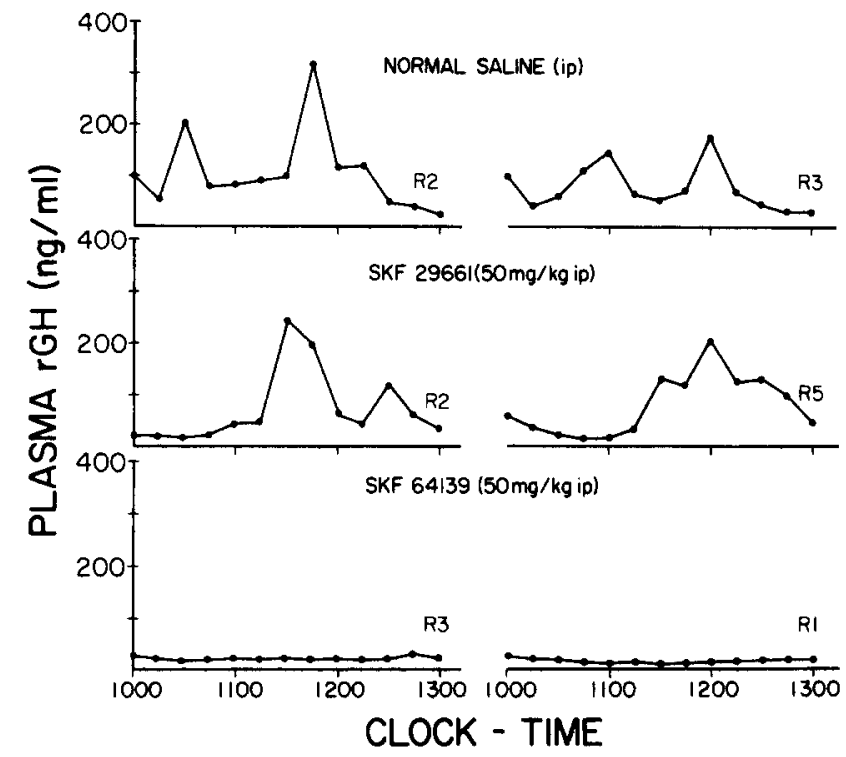

FIG. 2. Effects of SK\&F 29661 and SK\&F 64139 on episodic GH secretion in individual ovariectomized female rats. CNS NMT inhibition with SK\&F 64139 suppressed episodic GH secretion.

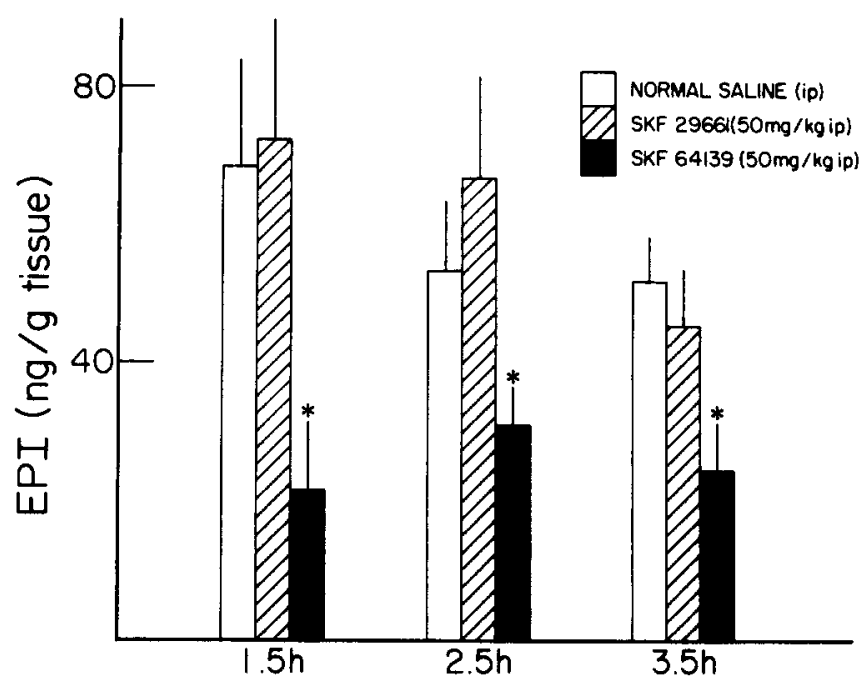

FIG. 3. Effects of SK\&F 29661 and SK\&F 64139 on the concentration of EPI in the hypothalamus $1.5,2.5$, and $3.5 \mathrm{hr}$ after drug administration at $0930 \mathrm{hr}$. SK\&F 64139 caused a significant reduction in EPI, but 29661 had no significant effect. * indicates $p<0.05$. Eight animals were in each treatment group. Vertical lines represent SE in this and subsequent figures.

ministered at a time (1105 hr) that coincided with the anticipated occurrence of a GH burst. In SK\&F 64139pretreated rats, clonidine caused a significant elevation in mean GH to levels seen during spontaneous pulses in untreated animals ( $p<0.0001$, Fig. 4).

To determine whether EPI was involved in morphine- 


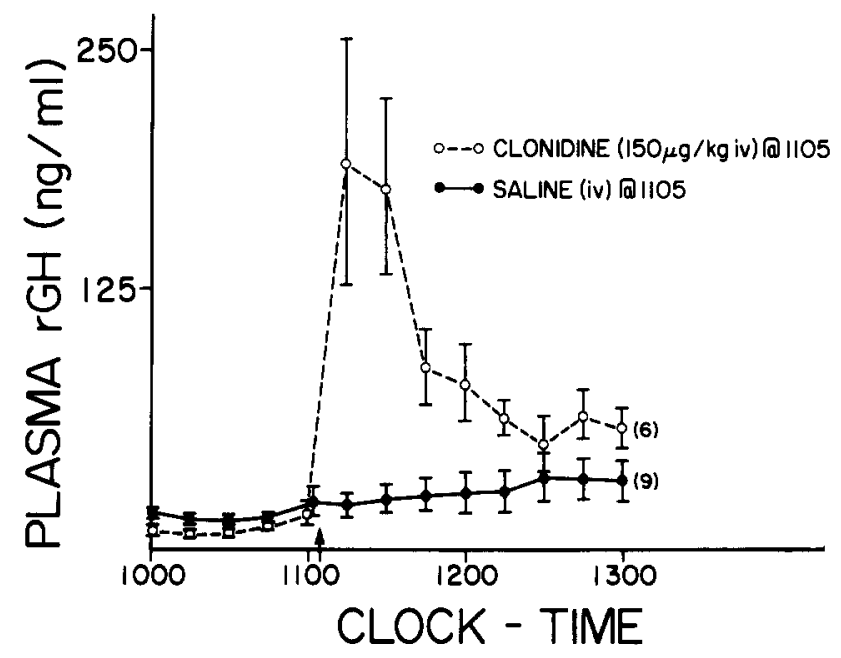

FIG. 4. Effect of clonidine, a centrally active alpha-adrenergic agonist, on GH secretion in SK\&F 64139-treated $(0930 \mathrm{hr})$ male rats. Clonidine administration caused a significant elevation in $\mathrm{GH}$ levels. In this and subsequent figures, numbers in parentheses refer to the number of animals in each treatment group. Arrow indicates clonidine or saline injection.

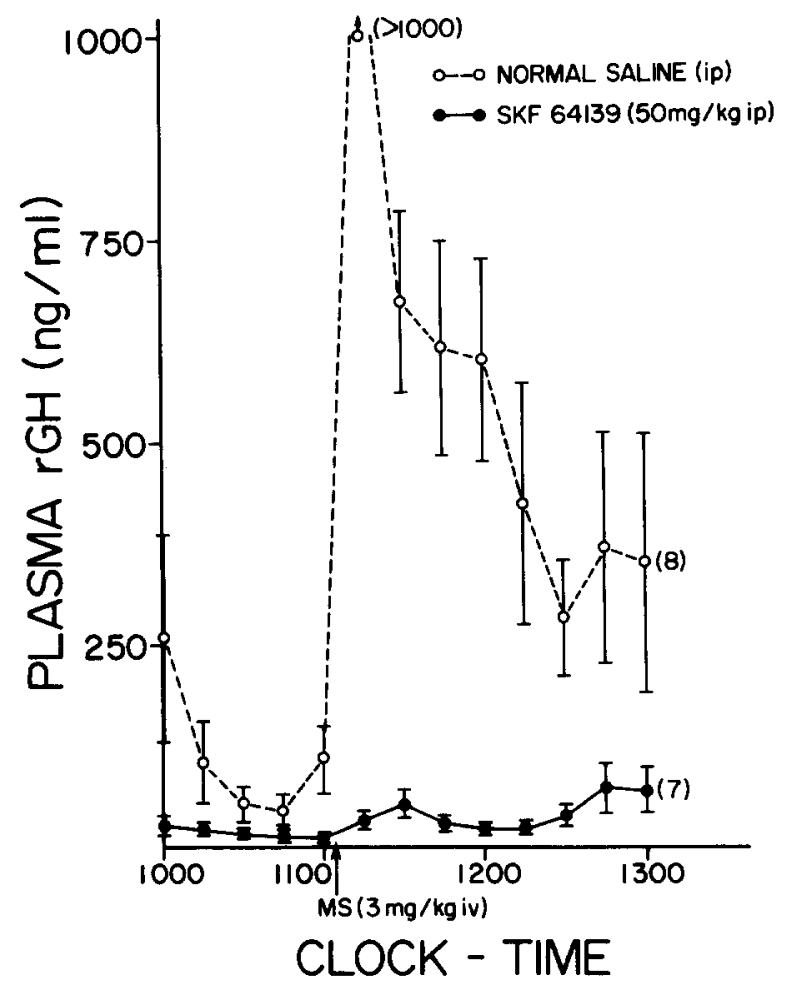

FIG. 5. Effects of morphine on GH secretion in SK\&F 64139- and saline-treated male rats. Morphine administration to saline-treated rats caused a significant elevation in GH levels. This effect was blocked completely by pretreatment with SK\&F 64139. Arrow indicates morphine injection.

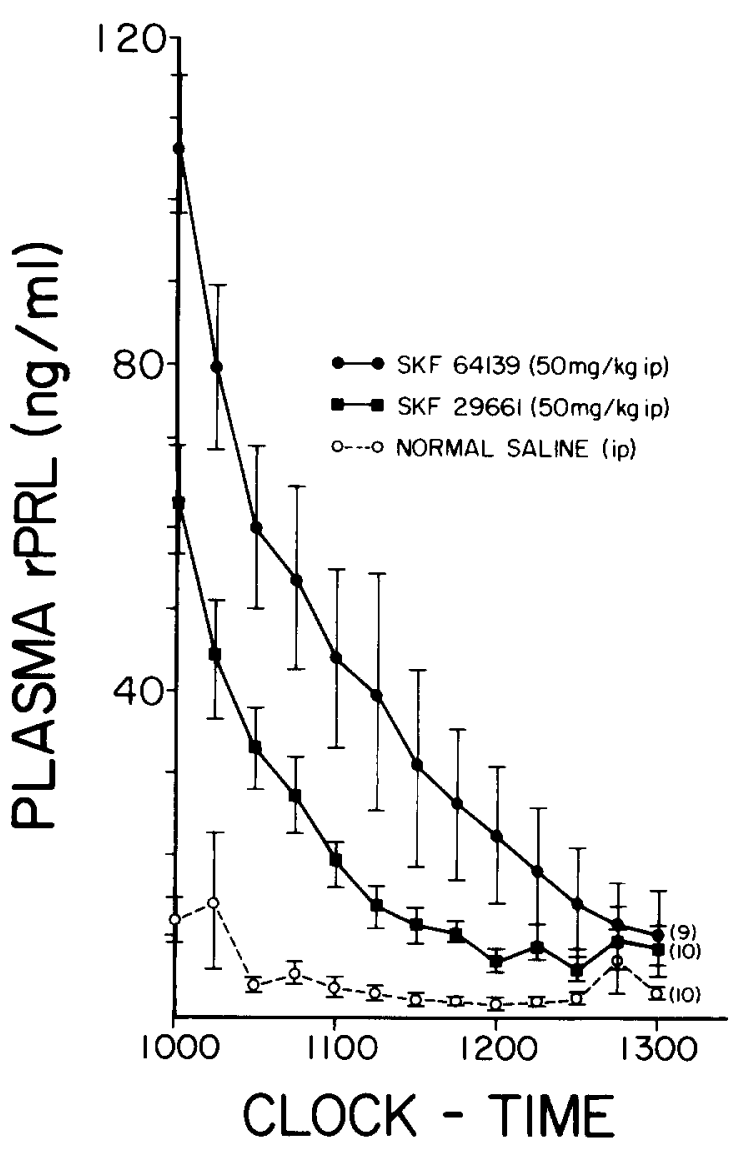

FIG. 6. Effects of the peripheral (SK\&F 29661) and central (SK\&F 64139) EPI synthesis inhibitors on plasma PRL levels in male rats. Both drugs caused a significant elevation in plasma PRL. The central NMT inhibitor, LY 78335, did not elevate PRL above basal levels (not shown, 56).

induced GH release, morphine sulfate $(3 \mathrm{mg} / \mathrm{kg} \mathrm{IV})$ was administered to saline- or SK\&F 64139-pretreated male rats. In the control group, morphine had an immediate stimulatory effect on GH that resulted in mean plasma levels $>1,000$ $\mathrm{ng} / \mathrm{ml}$ (Fig. 5). This stimulatory effect of morphine on GH was completely blocked by SK\&F 64139 . Morphine-induced GH release in the rat is inhibited by naloxone [19], indicating that this is a specific effect due to activation of opiate receptors.

\section{Effects of NMT Inhibitors on PRL in Male Rats}

SK\&F 64139 caused a significant increase in mean plasma levels of PRL (Fig. 6). Administration of the peripheral EPI synthesis inhibitor SK\&F 29661 also elevated PRL levels (Fig. 6). However, the other central NMT inhibitor, LY 78335 , did not significantly alter plasma PRL levels compared to the control group (data not shown, 50).

None of these drugs caused a discernible change in the animals' behavior, and, specifically, there were no indications that the drug-treated animals were stressed. 


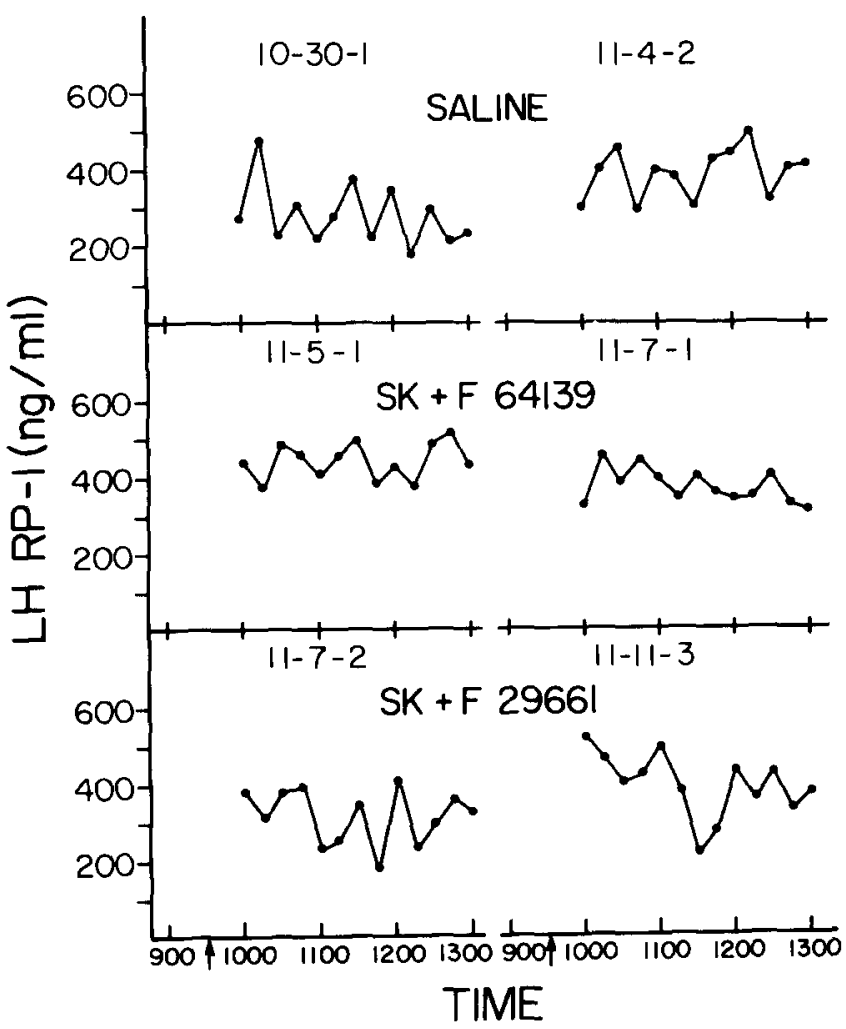

FIG. 7. Episodic LH secretion over a $3 \mathrm{hr}$ period in representative animals treated with saline or NMT inhibitors. Three-part number is animal identification code. Arrow denotes time of drug injection. Neither drug affected episodic LH release.

\section{Effects of NMT Inhibitors on $L H$ and PRL Secretion in Ovariectomized Female Rats}

Representative $3 \mathrm{hr}$ secretory profiles of LH in ovariectomized, hormonally untreated rats administered either saline, SK\&F 64139 or 29661 are illustrated in Fig. 7. Pulses of LH secretion were defined by criteria described previously [7]. Rats showed typical pulsatile LH secretion as described elsewhere [7]. Neither NMT inhibitor significantly affected the frequency or the mean pulse amplitude of LH pulses during the $3 \mathrm{hr}$ sampling period.

The administration of progesterone to estrogenpretreated animals elicited a surge of LH in saline controls (Fig. 8). This was completely blocked by the centrally acting EPI synthesis inhibitor, SK\&F 64139, and was also antagonized in a dose-related manner by SK\&F 83593, a second centrally acting EPI antagonist.

However, SK\&F 29661, the EPI synthesis inhibitor that fails to cross the blood brain barrier $[8,40]$, had no effect on the ovarian hormone-induced LH surge. None of the drugs tested altered "resting" levels of LH in oil vehicle-treated controls. SK\&F 64139 and 83593 significantly reduced hypothalamic concentrations of EPI in EB + progesteronetreated animals, but did not affect NE or DA levels, as described elsewhere [7].

SK\&F 64139 did not block the LH surge by inhibiting the

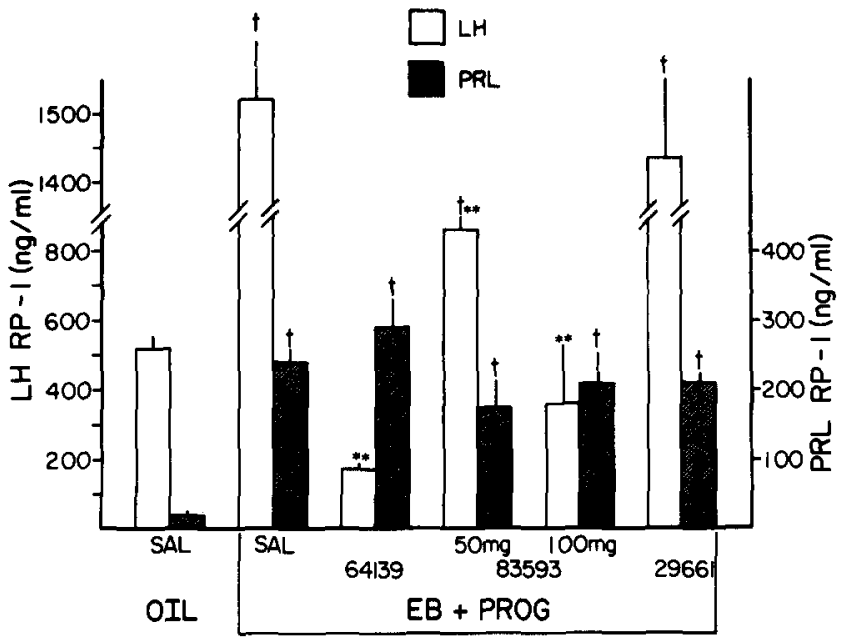

FIG. 8. Concentrations of $L H$ and PRL in plasma of ovariectomized rats given oil plus saline or estradiol (EB) and progesterone (PROG) plus saline or NMT inhibitors. $\nmid p 0.01$ vs oil-saline; ${ }^{* *} p<0.01$ vs EB + PROG and saline, based on analyses of variance and NewmanKeuls tests. n's $=8-10$.

TABLE 1

EFFECTS OF SK\&F 64139 ON LHRH-INDUCED LH RELEASE AFTER SEQUENTIAL ADMINISTRATION OF ESTRADIOL AND PROGESTERONE

\begin{tabular}{ll}
\hline \multicolumn{1}{c}{ Treatments } & $\begin{array}{c}\text { LH RP-1 } \\
\pm \text { SE (ng/ml) } \dagger\end{array}$ \\
\hline $\begin{array}{l}\text { 1. Saline (IP) + Saline (IV) } \\
\text { 2. Saline (IP) + LHRH } \\
\quad(100 \mathrm{ng} \text { IV) }\end{array}$ & $227 \pm 23$ \\
3. SK\&F 64139 (50 mg/kg IP) + LHRH & $628 \pm 60^{*}$ \\
$(100 \mathrm{ng}$ IV) & $520 \pm 27^{*}$ \\
\hline
\end{tabular}

${ }^{*} p<0.01$ vs saline (IP) + saline (IV); †blood samples taken $15 \mathrm{~min}$ after LHRH or saline (IV); $n$ 's $=6$.

response of gonadotropin-secreting cells to LHRH. Table 1 shows that circulating $\mathrm{LH}$ was markedly elevated $15 \mathrm{~min}$ after IV administration of LHRH, and that this effect was not significantly altered by pretreatment with the EPI synthesis inhibitor.

In contrast to the inhibitory effects of the EPI synthesis inhibitors on LH, these compounds had no effect on the steroid-induced increase in PRL (Fig. 8). However, because this increase of PRL is largely a consequence of the estradiol administered 3 days earlier, the third study tested whether SK\&F 64139 would prevent an acute rise in PRL induced by treatment with estradiol alone. As shown in Table 2, the EPI synthesis inhibitor did not block, and in fact tended to augment, the small rise in PRL observed on the day after estrogen treatment. 
TABLE 2

EFFECTS OF SK\&F 64139 ON ESTRADIOL-INDUCED PLASMA PRL IN OVARIECTOMIZED RATS

\begin{tabular}{lc}
\hline \multicolumn{1}{c}{ Treatments } & $\begin{array}{c}\text { PRL RP-1 } \\
\pm \text { SE }(\mathrm{ng} / \mathrm{ml})\end{array}$ \\
\hline 1. Oil + Saline & $3.9 \pm 0.8$ \\
2. Estradiol + Saline & $20.0 \pm 1.1^{*}$ \\
3. Estradiol + SK\&F 64139 & $41.2 \pm 7.2 \dagger$ \\
\hline
\end{tabular}

${ }^{*} p<0.05$ vs Oil + Saline; $\dagger p<0.01$ vs Oil + Saline, $p<0.05$ vs Estradiol + Saline; n's $=8$; blood samples were taken $4 \mathrm{hr}$ after the last injection of saline or SK\&F 64139.

DISCUSSION

\section{Growth Hormone}

The results of this study show that inhibition of CNS EPI synthesis by SK\&F 64139 and LY 78335 completely suppressed physiologic, episodic GH release in male and female rats. In contrast, the peripheral EPI synthesis blocker, SK\&F 29661, had no effect on GH secretion. The inhibition of episodic GH secretion by SK\&F 64139 was accompanied by a significant reduction in the hypothalamic concentration of EPI, whereas SK\&F 29661 had no effect. Earlier studies have shown that LY 78335 inhibited hypothalamic EPI synthesis [10]. These findings indicate that inhibition of CNS EPI synthesis rather than adrenal EPI synthesis is responsible.

In man, peripheral administration of EPI in doses sufficient to produce significant hyperglycemia did not induce $\mathrm{GH}$ release $[31,42,46]$. In contrast, large doses of EPI caused an increase in plasma GH levels in rhesus monkeys [32]. Intracerebroventricular or intravenous EPI administration to rats also caused release of bioassayable $\mathrm{GH}[36,37]$. However, these experiments were limited by the poor penetrability of the blood-brain barrier by EPI and the unavailability of agents that directly affect brain EPI neurotransmission. Data from the present experiments, in which selective EPI antagonists were used, indicate that the central EPI system has a major function in the generation of episodic $\mathrm{GH}$ secretion in the rat.

Inhibition of GH secretion by CNS EPI synthesis blockade could be due to decreased GH-releasing factor or increased SRIF release. Recent data [53] favor the former hypothesis because passive immunization against circulating SRIF did not reverse SK\&F 64139-induced TSH suppression, and previous studies have shown the TSH response to SRIF antiserum, which was inhibited by SK\&F 64139 [53], is mediated by thyrotropin releasing hormone [4].

Previous studies have shown that clonidine restores pulsatile $\mathrm{GH}$ release in male rats after blockade of NE and EPI synthesis with FLA-63, a DA-beta-hydroxylase inhibitor [51]. In the present study, clonidine administration to NMTinhibited animals elevated GH to levels that occur during episodic release. Clonidine also stimulates GH secretion in man and several species of experimental animals $[3,9,24$, $26,51]$. The stimulatory action of clonidine is most likely due to activation of postsynaptic alpha-adrenergic receptors. Clonidine activates postsynaptic or presynaptic EPI receptors in discrete brain regions [11], It is not possible at present to determine whether the effect of clonidine is due to activation of receptors normally occupied by NE or EPI. However, the ability of clonidine to stimulate $\mathrm{GH}$ release in NMT-inhibited rats demonstrates that the EPI synthesis inhibitor, SK\&F 64139, does not compromise the ability of the pituitary gland to release $\mathrm{GH}$.

Morphine and the endogenous opioid peptides, metenkephalin and beta-endorphin, have a potent stimulatory effect on GH secretion in numerous experimental animals, an effect prevented by the specific opiate receptor blocker, naloxone $[5,15,19,29,54]$. Furthermore, the synthetic enkephalin analogue, FK-33-824, causes GH release in man [13]. None of the opioids appear to act directly at the pituitary level, and it is likely that they influence the release of $\mathrm{GH}$ either by modulating the secretion of releasing-inhibiting factors and/or by influencing monoaminergic neurotransmission [41]. Evidence to support the latter hypothesis was provided in a recent study demonstrating that alphaadrenergic receptor blockade with phenoxybenzamine or inhibition of NE and EPI synthesis with diethyldithiocarbamate, a DA-beta-hydroxylase inhibitor, abolished the GHreleasing effect of morphine on $\mathrm{GH}$ in the rat [19]. These effects were attributed to noradrenergic mechanisms. Data from the present study suggest that morphine enhances GH secretion by activation of CNS EPI systems, because the selective EPI antagonist, SK\&F 64139, completely blocked morphine-induced $\mathrm{GH}$ release. These results do not necessarily exclude a similar role for $\mathrm{NE}$.

\section{Prolactin}

The tetrahydroisoquinoline NMT inhibitors, SK\&F 64139 and 29661, both elevated plasma PRL levels. The mechanism underlying this effect is unknown but does not appear to be related to EPI synthesis inhibition, because elevation of PRL was not observed with the benzylamine NMT inhibitor, LY 78335. It is possible that the SK\&F compounds exert a direct action on pituitary lactotrophs (i.e., DA receptor blockade) unrelated to their effects on EPI synthesis.

\section{Luteinizing Hormone}

The present results suggest that the stimulatory feedback actions of the ovarian hormones on LH release may be mediated by activation of the central epinephrine-containing systems. The lack of an inhibitory effect by SK\&F 29661 , which does not inhibit EPI synthesis in the brain, and the failure of SK\&F 64139 to block LH release elicited by exogenous LHRH point to a central site of action for the drugs. The present experiments do not necessarily rule out a similar role for norepinephrine but they do appear to indicate that EPI may be of primary importance in regulation of $\mathrm{LH}$ secretion.

This hypothesis was further tested in EPI turnover studies (manuscript in preparation). A decline of hypothalamic EPI was observed after $\alpha$-methyltyrosine in estrogen plus progesterone-treated animals, as compared to the vehicle controls, while estrogen alone had no effect. Because the depletion of catecholamine after $\alpha$-methyltyrosine depends upon the rate of nerve impulse flow, with more decline associated with increased neuronal activity [1], these results may be interpreted to mean that estradiol plus progesterone treatment enhances the turnover of EPI in the hypothalamus during the LH surge. These findings are, therefore, consistent with the hypothesis that the stimulatory feedback effects 
of the ovarian hormones on LH may involve activation of epinephrine systems.

It is possible that EPI neurons stimulate either directly or indirectly, the release of LHRH. In addition to enhancing hypothalamic EPI turnover, the administration of estradiol and progesterone produced sequential accumulation followed by a decline of LHRH in the median eminence and arcuate nucleus prior to the LH surge [47], and there is evidence for release of LHRH into the pituitary portal system at this time [44]. Further investigations are continuing to test whether EPI synthesis inhibitors prevent these ovarian hormone-induced changes in LHRH. If so, this could be considered evidence that central EPI systems regulate the neurosecretion of LHRH.

\section{ACKNOWLEDGEMENTS}

The gift of SK\&F 64139,83593 and 29661 by Dr. R. Pendleton and Smith Kline \& French Laboratories and of LY 78335 by Dr. R. Fuller and Eli Lilly Company Research Laboratories is appreciated greatly. The generous provision of radioimmunoassay materials by the National Pituitary Agency is acknowledged.

\section{REFERENCES}

1. Anden, N. E., H. Corrodi, A. Dahlstrom, K. Fuxe and T. Hökfelt. Effects of tyrosine hydroxylase inhibition on the amine levels of central monoamine neurons. Life Sci. 5: 561-568, 1966.

2. Brazeau, P., W. Vale, R. Burgus, N. Ling, M. Butcher, J. Rivier and R. Guillemin. Hypothalamic polypeptide that inhibits the secretion of immunoreactive pituitary growth hormone. Science 179: 77-79, 1973.

3. Chambers, J. W. and G. M. Brown. Neurotransmitter regulation of growth hormone and ACTH in the rhesus monkey: effects of biogenic amines. Endocrinology 98: 420-428, 1976.

4. Chihara, K., A. Arimura, M. Chihara and A. V. Schally. Studies on the mechanism of growth hormone thyrotropin responses to somatostatin antiserum in anesthetized rats. Endocrinology 103: 1916-1923, 1978.

5. Chihara, K., A. Arimura, D. H. Coy and A. V. Schally. Studies on the interaction of endorphins, substance $P$ and endogenous somatostatin in growth hormone and prolactin release in rats. Endocrinology 102: 281-290, 1978.

6. Clemens, J. A. and C. J. Scharr. Control of prolactin secretion in mammals. Fedn Proc. 39: 2588-2592, 1980.

7. Crowley, W. R., L. C. Terry and M. D. Johnson. Evidence for the involvement of central epinephrine systems in the regulation of luteinizing hormone, prolactin, and growth hormone release in female rats. Endocrinology 110: 1102-1107, 1982.

8. Crowley, W. R. and L. C. Terry. Effects of an epinephrine synthesis inhibitor, SK\&F 64139, on the secretion of luteinizing hormone in ovariectomized female rats. Brain Res. 204: 231235,1981

9. Durand, D., J. B. Martin and P. Brazeau. Evidence for a role of alpha-adrenergic mechanisms in regulation of episodic growth hormone secretion in the rat. Endocrinology 100: 722-728, 1977.

10. Fuller, R. W. and K. W. Perry. Lowering of epinephrine concentration in rat brain by 2,3-dichloro-alphamethylbenzylamine, an inhibitor of norepinephrine N-methyltransferase. Biochem. Pharmac. 26: 2087-2090, 1977.

11. Fuxe, K., G. Jonsson, P. Bolme, K. Anderson, L. F. Agnati, M. Goldstein and T. Hökfelt. Reduction in adrenaline turnover in cardiovascular areas of rat medulla oblongata by clonidine. Acta physiol. scand. 107: 177-179, 1979.

12. Goldstein, M., J. Y. Lew, Y. Matsumoto, T. Hökfelt and K. Fuxe. Localization and function of PNMT in the central nervous system. In: Psychopharmacology: A Generation of Progress, edited by M. A. Lipton, A. DiMascio and K. F. Killam. New York: Raven Press, 1978, pp. 261-269.

13. Graffenreid, B., E. Del Pozo, J. Roubicek, E. Krebs, W. Poldinger, P. Burmeister and L. Kerp. Effects of the synthetic enkephalin analogue FK 33-824 in man. Nature, Lond. 272: $729-730,1978$.

14. Hökfelt, T., R. Elde, K. Fuxe, O. Johanssen, A. Ljungdahl, M. Goldstein, R. Luft, S. Efendic, G. Nilsson, L. Terenius, D. Ganten, S. L. Jeffcoate, J. Rehfeld, S. Said, M. Perez de la Mora, L. Possani, R. Tapia, L. Teran and R. Palacios. Aminergic and peptidergic pathways in the nervous system with special reference to the hypothalamus. In: The Hypothalamus, edited by S. Reichlin, R. J. Baldessarini and J. B. Martin. New York: Raven Press, 1978, pp. 69-135.
15. Imura, H., Y. Kato, H. Katakami and N. Matsushita. Effect of CNS peptides on hypothalamic regulation of pituitary secretion. In: Neurosecretion and Brain Peptides, edited by J. B. Martin, S. Reichlin and K. L. Bick. New York: Raven Press, 1981, pp. 557-570.

16. Kalra, S. P., C. L. Chen and J. A. Clemens. Effect of norepinephrine synthesis inhibitors and a dopamine agonist on hypothalamic LHRH, serum gonadotropin and prolactin levels in gonadal steroid treated rats. Acta endocr. 89: 1-9, 1978.

17. Kalra, P. S., S. P. Kalra, L. Krulich, C. P. Fawcett and S. M. McCann. Involvement of norepinephrine in transmission of the stimulatory influence of progesterone on gonadotropin release. Endocrinology 90: 1168-1176, 1972.

18. Kalra, S. P. and S. M. McCann. Effects of drugs modifying catecholamine synthesis on plasma LH and ovulation in the rat. Neuroendocrinology 15: 79-91, 1974.

19. Koenig, J., M. A. Mayfield, R. J. Coppings, S. M. McCann and L. Krulich. Role of central nervous system neurotransmitters in mediating the effects of morphine on growth hormone- and prolactin-secretion in the rat. Brain Res. 197: 453-468, 1980.

20. Koslow, S. H. and M. Schlumpf. Quantitation of adrenaline in rat brain nuclei and areas by mass fragmentography. Nature 251: 530-531, 1974.

21. Krulich, L. Central neurotransmitters and the secretion of prolactin, GH, LH and TSH. A. Rev. Physiol. 41: 603-615, 1979.

22. Lal, S. and J. B. Martin. Neuroanatomy and neuropharmacological regulation of neuroendocrine function. In: Handbook of Biological Psychiatry. Part III: Brain Mechanisms and Abnormal Behavior-Genetic and Neuroendocrinology, edited by $\mathrm{H}$. M. van Praag, M. H. Lader, O. J. Rafaelsen and E. J. Sachar. New York: Marcel Dekker, 1980, pp. 101-167.

23. Lal, S., C. E. De La Vega, T. L. Sourkes and H. G. Friesen. Effect of apomorphine on growth hormone and folliclestimulating hormone levels in human serum. J. clin. Endocr. Metab. 37: 719-724, 1973.

24. Lal, S., G. Tolis, J. B. Martin, G. M. Brown and H. Guyda. Effect of clonidine on growth hormone, prolactin, luteinizing hormone, follicle-stimulating hormone, and thyroid-stimulating hormone in the serum of normal man. J. clin. Endocr. Metab. 41: 827-832, 1975.

25. Lawson, D. M. and R. R. Gala. The influence of adrenergic, dopaminergic, cholinergic and serotoninergic drugs on plasma prolactin levels in ovariectomized, estrogen-treated rats. Endocrinology 96: 313-318, 1975.

26. Lovinger, R., J. Holland, S. Kaplan, M. Grumbach, A. J. Boryczka, R. Shackelford, J. Salmon, I. A. Reid and W. F. Ganong. Pharmacological evidence for stimulation of growth hormone secretion by a central adrenergic system in dogs. Neuroscience 1: 443-450, 1976.

27. MacLeod, R. M. Regulation of prolactin secretion. Front. Neuroendocr. 4: 169-194, 1976.

28. Martin, J. B. Functions of central nervous system neurotransmitters in regulation of growth hormone secretion. Fedn Proc. 39: $2902-2906,1980$. 
29. Martin, J. B., P. Brazeau, G. S. Tannenbaum, J. O. Willoughby, J. Epelbaum, L. C. Terry and D. Durand. Neuroendocrine organization of growth hormone regulation. In: The Hypothalamus, edited by S. Reichlin, R. J. Baldessarini and J. B. Martin. New York: Raven Press, 1978, pp. 329-357.

30. Martin, J. B., D. Durand, W. Gurd, G. Faille, J. Audet and P. Brazeau. Neuropharmacological regulation of episodic growth hormone and prolactin secretion in the rat. Endocrinology 102: $106-113,1978$.

31. Massara, F. and E. Strumina. Increase in plasma growth hormone concentration in man after infusion of adrenalinepropranolol. J. Endocr. 47: 95-100, 1970.

32. Meyer, V. and K. Knobil. Growth hormone secretion in the unanesthetized rhesus monkey in response to noxious stimuli. Endocrinology 80: 163-171, 1967.

33. Moore, R. Y. and F. E. Bloom. Central catecholamine neuron systems: anatomy and physiology of the dopamine systems. $A$. Rev. Neurosci. 1: 129-169, 1978.

34. Moore, R. Y. and F. E. Bloom. Central catecholamine neuron systems: anatomy and physiology of the norepinephrine and epinephrine systems. A. Rev. Neurosci. 2: 113-168, 1979.

35. Muller, E. E., G. Nistico and U. Scapagnini. Brain neurotransmitters and the regulation of anterior pituitary function. In: Neurotransmitters and Anterior Pituitary Function. New York: Academic Press, 1977, pp. 220-323.

36. Muller, E. E., P. Dal Pra and A. Pecile. Influence of brain neurohumors injected into the lateral ventricle of the rat on growth hormone release. Endocrinology 83: 893-896, 1968.

37. Muller, E. E., T. Saito, A. Arimura and A. V. Schally. Blockade of release of growth hormone by brain norepinephrine depletors. Endocrinology 80: 471-476, 1967.

38. Palkovits, M., M. Brownstein, J. M. Saavedra and J. Axelrod. Norepinephrine and dopamine content of hypothalamic nuclei of the rat. Brain Res. 77: 137-149, 1974.

39. Pendleton, R. G., J. P. McCafferty and J. M. Roesler. Effects of PNMT inhibitors upon cardiovascular changes induced by hemorrhage in the rat. Eur. J. Pharmac. 66: 1-10, 1980.

40. Pendleton, R. G., G. Gessner, G. Weiner, B. Jenkins, J. Sawyer, W. Bondinell and A. Intoccia. Studies on SK\&F 29661, an organ specific inhibitor of phenylenthanolamine-Nmethyltransferase. J. Pharmac. exp. Ther. 208: 24-30, 1979.

41. Rivier, C., W. Vale, N. Ling, M. Brown and R. Guillemin. Stimulation in vivo of the secretion of prolactin and growth hormone by beta-endorphin. Endocrinology 100: 238-241, 1977.
42. Roth, J., M. Glick, R. S. Yalow and R. A. Berson. Hypoglycemia: a potent stimulus to secretion of growth hormone. Science 140: 987-988, 1963.

43. Rubinstein, L. and C. H. Sawyer. Role of catecholamines in stimulating the release of pituitary ovulatory hormone(s) in rats. Endocrinology 86: 988-999, 1970.

44. Sarkar, D. K. and G. Fink. Luteinizing hormone-releasing factor in pituitary stalk plasma from long-term ovariectomized rats: effects of steroids. J. Endocr. 86: 511-524, 1980.

45. Sauter, A. M., J. Y. Lew, Y. Baba and M. Goldstein. Effect of phenylethanolamine $\mathrm{N}$-methyltransferase and dopamine-betahydroxylase inhibition on epinephrine levels in the brain. Life Sci. 21: 261-266, 1977

46. Schalch, D. S. The influence of physical stress and exercise on growth hormone and insulin secretion in man. J. Lab. clin. Med. 69: 256-269, 1967

47. Simpkins, J. W., P. S. Kalra and S. P. Kalra. Temporal alterations in luteinizing hormone releasing hormone concentrations in several discrete brain regions: effects of estrogenprogesterone and norepinephrine synthesis inhibition. Endocrinology 107: 573-577, 1980.

48. Stevens, R. W. and D. M. Lawson. The influence of estrogen on plasma prolactin levels induced by thyrotropin releasing hormone (TRH), clonidine and serotonin in ovariectomized rats. Life Sci. 20: 261-265, 1977.

49. Tannenbaum, G. S. and J. B. Martin. Evidence for an exogenous ultradian rhythm governing growth hormone secretion in the rat. Endocrinology 98: 562-570, 1976.

50. Terry, L. C., W. R. Crowley and M. D. Johnson. Regulation of episodic growth hormone secretion by the central epinephrine system. J. clin. Invest. 69: 104-112, 1982.

51. Terry, L. C. and J. B. Martin. Evidence for alpha-adrenergic regulation of episodic growth hormone and prolactin secretion in the undisturbed male rat. Endocrinology 108: 1869-1873, 1981.

52. Terry, L. C. and J. B. Martin. The effects of lateral hypothalamic-medial forebrain stimulation and somatostatin antiserum on pulsatile growth hormone secretion in freelybehaving rats: evidence for a dual regulatory mechanism. Endocrinology 109: 622-627, 1981.

53. Terry, L. C. Role of the central adrenergic system in episodic secretion of thyroid stimulating hormone. Ann. Neurol. 10: 81 (abstract no. 37), 1981.

54. Van Vugt, D. A. and J. Meites. Influence of endogenous opiates on anterior pituitary function. Fedn Proc. 39: 2533-2538, 1980. 